\title{
Individual and community resilience in natural disaster risks and pandemics (covid-19): risk and crisis communication
}

\author{
Panagiotis V. Katsikopoulos ${ }^{1}$
}

Received: 16 July 2020 / Accepted: 25 August 2020 / Published online: 10 September 2020

(c) Springer-Verlag GmbH Germany, part of Springer Nature 2020

\begin{abstract}
Civil Protection and disaster risk specific agencies legally responsible to enhance individual and community resilience, still utilize in their risk and crisis communication efforts, the "deficit model" even though its basic assumption and approach have been criticized. Recent studies indicate that information seeking behavior is not necessarily a measure of enhanced individual preparedness. A qualitative change from "blindly" following directions to practicing emergency planning and becoming your own disaster risk manager is required. For pandemics, the challenge is even more complicated due to their unique characteristics. Community based exercises (CBEx), a framework concept encompassing a variety of interactive activities, have recently started being utilized to develop resilience amongst citizens. Existing models of resilience can pinpoint to the required knowledge, skills and attitude. Research in the factors influencing behavioral change could offer new understanding of the interplay between cognitive and demographic drivers/factors of resilience. Such knowledge could be utilized for setting targeted objectives, developing appropriate activities and the corresponding training for the CBEx facilitators. Despite the importance of preparation, the current covid-19 crisis indicates that high levels of adaptive resilience can be displayed even in the absence of any risk communication effort beforehand by utilizing a pre-existing collective understanding of the system situation.
\end{abstract}

Keywords COVID-19 - Corona virus · Risk and crisis communication · Resilience · Community based exercises $\cdot$ Crisis management

Panagiotis V. Katsikopoulos pkatsikopoulos@gscp.gr; pkatsikopoulos@hua.gr

1 General Secretariat for Civil Protection/Ministry of Citizen Protection, 37-39 Kifisias Ave., 15123 Marousi, Greece 
One of the fundamental principles of emergency planning, that every student has been taught, is that it takes place in an environment of apathy, even resistance, and with limited resources (FEMA 2006). This is even more valid for risk communication also termed "public preparedness education" in the emergency management field. Governments and citizens (both faced with limited resources and attention) tend to consider prudent to focus on "frequently" occurring disaster risks at the national and/or local level, as these risks are naturally presumed to be of the highest priority (Wilkinson et al. 2017). It is an issue of risk assessment and management. The 34 countries participating in the Union Civil Protection Mechanism regularly submit to the European Commission (EC) their national risk assessment. In the latest report available (European Commission 2017), one finds listed as priority risk along earthquakes, floods, and forest fires, the biological threat/pandemics risk as well. Only nine countries (Cyprus, France, Greece, Italy, Montenegro, North Macedonia, Portugal, Spain, and Turkey) have not included the latter.

The risk and crisis communication mandate rests predominantly on Civil Protection Authorities and disaster risk specific agencies (e.g. responsible for earthquakes, floods, public health, etc.) at central, regional, and local level. To fulfill their mandate they provide information about various disaster risks in order to enhance individual and community disaster preparedness. The staff of these organizations has, in general, limited knowledge of the state of the art in the relevant to risk communication scientific fields and lacks the necessary links with academia that could inform their effort (Haddow et al. 2011). As a result, the approach has been and is still based on the so-called "deficit model" even though its basic assumption (the public is an empty vessel to be filled with information) has been criticized (Nisbet and Mooney 2007; Boersma et al. 2017). A number of alternative two-way interaction models (also called engagement models) have been proposed (Boersma et al. 2017). EC has funded relatively few programs to experiment with the so-called engagement models (Boersma et al. 2017; Musacchio and Solarino 2019; Yovkov et al. 2015). In Europe and the USA the assessment is that despite more use of various two-way communication approaches, the efforts still fall short of inducing the necessary changes in behavior (Boersma et al. 2017; National Academies of Sciences, Engineering, and Medicine 2018). The conclusion is that more research is needed to determine how to motivate behavior change, as well as to identify what other factors contribute to successful public disaster education campaigns.

The information provided to the public usually covers facts for a) basic understanding of specific disaster risks (e.g. earthquakes, floods, etc.), and b) directions to strengthen prevention, inform and educate about the actions and behavior to decrease personal exposure to each specific risk [e.g. for earthquakes: "stop, drop under or beside, and cover" against the natural tendency to flight - evacuate the building during shaking, for severe weather phenomena: having a stock of emergency supplies (water, canned food, etc)], and how to make an individual and/or household emergency plan. It is commonplace to specifically address certain vulnerable populations, like school students. The websites of the responsible authorities and of other organizations (NGOs, professional associations, civil society) are full with information of that sort. Nevertheless, the effectiveness of 
the means used (traditional, like pamphlets and contemporary, like social media) has not really been the subject of serious study.

Recent studies (Maduz et al. 2019; Kohn et al. 2012) have indicated that information seeking behavior is not necessarily a measure of enhanced preparedness. The actual challenge is to make the transition from the so-called "weak preparation" (like storing emergency supplies) to "hard preparation" (e.g. establishing an individual and/or household emergency plan). In a sense, what is required is a qualitative change from "blindly" following some directions to cooperating with others to practice emergency planning and even further, become your own emergency or even disaster risk manager.

The concept of resilience with the abundance of definitions (Alexander 2013) and the various numbers of dimensions (called domains, properties, or stages) that have been proposed to operationalize it, can be useful in informing that goal. Especially, the definition of resilience as "the ability to prepare and plan for, absorb, recover from, or more successfully adapt to actual or potential adverse events" (National Research Council 2012), the proposition that it encompasses the properties of robustness, redundancy, resourcefulness, and rapidity (Bruneau et al. 2003; Tierney and Bruneau 2007), and the view (Cutter et al. 2008) that it consists of inherent resilience and adaptive resilience (through improvisation and learning), when applied to individuals and groups can guide us. They help pinpoint to the knowledge, skills and attitude we need to focus on and communicate to the public in order to enhance its resilience level. In conjunction with individual disaster preparedness surveys that could help identify barriers and possible triggers for its enhancement, they can provide paths to research that could offer some interesting and useful insights for effective risk and crisis communication.

Depending on the application unit, we can talk about resilience of individuals, infrastructures, institutions, ecosystems and communities (Kahan 2015). It is important to realize that there is inherent, not well understood, interaction between them, e.g. when citizens know what to expect from the authorities then the latter's emergency plans have an increased effectiveness and efficiency and vice versa.

Pandemics risk, like covid-19, displays a number of characteristics differentiating it from natural disasters, namely:

- Relatively infrequent occurrence that "deprives" the public from firsthand experience (recent epidemics SARS, MERS were contained fairly easily).

- Pandemics risk and its management are surrounded by lots of unknowns and uncertainty, including variable positions by experts, sometimes even seemingly changing over time [Adams (2003) considers that it belongs to the so-called "virtual risks"].

- Early recognition of the forthcoming crisis is not (always) obvious, resulting in challenges in sense-making.

- The guidelines (social distancing, wearing gloves, washing hands frequently, avoiding vulnerable friends and family, staying at home, not going to work, etc.) the public is "advised" - "ordered" to follow are "unnatural". They oppose people's tendency of wanting to spend even more time together when confront- 
ing a disaster situation. It is this very closeness and camaraderie that have been observed to build people's adaptive resilience in natural disasters.

- Emergency response lasts much longer (many months) as compared to natural disasters (days to weeks). In addition, as by definition emergency response ends when the situation stabilizes i.e. threat to life and property has fallen down to the pre-emergency level (FEMA 2006), even the end is not straightforward but a matter of debate in pandemics.

- In pandemics the public has an apparently passive role contrary to natural disasters where the public actively participates in response and recovery activities.

It should also be pointed out that pandemics is probably the only disaster risk, that the protective measures bear the potential to cause individual and community resilience decreases in the future, as they negatively influence community competence factors (psychopathologies, health \& wellness (Brooks et al. 2020)) of the population and especially of vulnerable groups (elderly, people with chronic sickness, etc.) as well as economic factors (Cutter et al. 2008). Therefore, the main question is "How do you protect now, without negatively affecting long term resilience at the individual and community level?" More specifically, what should be the characteristics of the risk and crisis communication campaigns as far as message content and frequency of repetition, how is the effect of the unknowns on the message content managed, what are the possible shortcomings of "the war against an invisible enemy" model (adopted in many countries), what is an effective and viable mixture of coercion and persuasion, etc.

All these together form a quite different and more complicated environment for the risk and crisis communication than the one we are used to in natural disasters. They superimpose on the general risk communication challenges referred to previously.

Besides specific disaster risk communication, risk communication efforts should be targeted to instilling to the public the emergency planning toolbox of knowledge, skills, and attitude, i.e. identifying and assessing disaster risks and vulnerabilities, understanding that preparation is key, and that key to preparation is planning together with others (family members, co-workers, neighbors, etc.), and finally acquiring the mindset for the implementation of a plan and the need to improvise if necessary. The traditional one-way communication approach is not an effective way to achieve these objectives.

A framework concept encompassing a variety of two-way communication interactive activities on the above topics altogether in one event, is the so-called Community based exercise (CBEx). CBEx have recently started being utilized with main objective to develop resilience amongst citizens (Yovkov et al. 2015). A CBEx uses as trainers/facilitators experts and personnel of organizations that are part of the civil protection system and utilizes the participation of other stakeholders that are part of a community.

The choice of the specific objectives, topics and the design of activities (facilitated work sessions, workshops, competitions, demonstrations, short exercises, games, etc.) for the various target groups of a community, are of great importance for the effectiveness of the effort. Research in the factors that influence behavioral 
change could offer new and practical understanding of the interplay between cognitive and demographic drivers/factors of preparedness/resilience. Subsequently, such knowledge could be utilized for setting clearly targeted objectives, developing appropriate activities and the corresponding training for the trainers/facilitators.

In particular regarding the pandemics risk, it is necessary to understand how the specific characteristics listed before, affect and shape the risk communication effort regarding "hard preparations" as it is of a quite different nature as compared to natural disaster risks. It is also interesting to study the interplay between risk and crisis communication in pandemics as it is also defined by the pandemics' very characteristics.

As a final point, we turn to the actual reason we care about all that, which is to see how individual, community, societal resilience is realized in time of crisis and identify ways to enhance it. For an effective crisis management effort, Stern (2014) has emphasized the importance of early recognition of a forthcoming crisis, expedient sense-making and use of an appropriate narrative to guide crisis communication by the crisis management team. The distinguishing features of risk communication and crisis communication have been stated by Reynolds and Seeger (2005). An underlying assumption is that the latter builds on the former. We would like to claim that, in the presence of early recognition and expedient sense-making, it is possible to display high levels of adaptive resilience even in the absence of any risk communication campaign beforehand by utilizing a pre-existing collective understanding of the system situation. Specifically a, well known to all (crisis managers and public), weakness (e.g. the quite limited capacity of the health system) can, almost explicitly, serve as the critical element in the persuasion of the public to adhere to strict measures (movement restriction, etc.). In that way, a weakness is turned around, becoming instead an enabler for crisis communication success. Unexpected allies can arise in dire situations. One should not rely on this possibility but it exists and sometimes can save even the ones that have not prepared but showed a particular type of vigilance in crisis.

Acknowledgements The author would like to acknowledge colleagues and students over the years and especially Th. Sfetsos (NCSR Demokritos) and P. Dimitropoulou (Univ. of Crete) for fruitful discussions.

\section{Compliance with ethical standards}

Conflict of interest The author declares that he has no conflict of interest.

\section{References}

Adams J (2003) Risk and morality: three framing devices. In: Ericson R, Doyle A (eds) Risk and morality. University of Toronto Press, Toronto, pp 87-104

Alexander DE (2013) Resilience and disaster risk reduction: an etymological journey. Nat Hazards Earth Syst Sci 13:2707-2716. https://doi.org/10.5194/nhess-13-2707-2013

Boersma KF, Terpstra T, Comes T, Stanciugelu I, Allen D et al (2017) Communicating disaster risk. In: Poljanšek K, Marin Ferrer M, De Groeve T, Clark I (eds) Science for disaster risk management 
2017: knowing better and losing less. EUR 28034 EN, Publications Office of the European Union, Luxembourg, pp 387-440 and refs therein. https://doi.org/10.2788/842809

Brooks SK, Webster RK, Smith LE, Woodland L, Wessely S, Greenberg N, Rubin GJ (2020) The psychological impact of quarantine and how to reduce it: rapid review of the evidence. Lancet 395:912-920

Bruneau M, Chang SE, Eguchi RT, Lee GC, O’Rourke TD, Reinhorn AM et al (2003) A framework to quantitatively assess and enhance the seismic resilience of communities. Earthq Spectra 19(4):733752. https://doi.org/10.1193/1.1623497

Cutter SL, Barnes L, Berry M, Burton C, Evans E, Tate E, Webb J (2008) A place-based model for understanding community resilience to natural disasters. Glob Environ Change 18:598-606

European Commission (2017) Commission Staff Working Document, Overview of Natural and Manmade Disaster Risks the European Union may face, SWD(2017) 176 final

FEMA (2006) Fundamentals of Emergency Management Online Textbook. FEMA Higher Education Project. http://www.training.fema.gov/EMIWeb/edu/fem.asp

Haddow GD, Bullock JA, Coppola DP (2011) Introduction to emergency management, 4th edn. Butterworth-Heinemann, Burlington, pp 97-131

Kahan JH (2015) Resilience Redux: Buzzword or basis for Homeland Security. Homeland Security Affairs 11, article 2

Kohn S, Eaton J, Feroz S, Bainbridge A, Hoolachan J, Barnett D (2012) Personal disaster preparedness: an integrative review of the literature. Disaster Med Public Health Prep 6:217-231. https://doi. org/10.1001/dmp.2012.47

Maduz L, Roth F, Prior T, Käser M (2019) Individual disaster preparedness: explaining disaster-related information-seeking and preparedness behaviour in Switzerland, risk and resilience report. Center for Security Studies (CSS), ETH Zürich

Musacchio G, Solarino S (2019) Seismic risk communication: an opportunity for prevention. Bollettino di Geofisica Teorica ed Applicata 60:295-314

National Academies of Sciences, Engineering, and Medicine (2018) Emergency alert and warning systems: current knowledge and future research directions. The National Academies Press, Washington, DC. https://doi.org/10.17226/24935

National Research Council (2012) Disaster resilience: a national imperative. The National Academies Press, Washington, DC. https://doi.org/10.17226/13457

Nisbet MC, Mooney C (2007) Framing Science. Science 316:56

Reynolds B, Seeger MW (2005) Crisis and emergency risk communication as an integrative model. J Health Commun 10:43-55

Stern E (2014) From warning to sense-making: understanding, identifying and responding to strategic crises. OECD, Paris

Tierney K, Bruneau M (2007) Conceptualizing and measuring resilience. a key to disaster loss reduction. TR News 250:14-18

Wilkinson E, Surminski S, Peters K, Oliveira CS, Mysiak J et al (2017) Managing disaster risk. In: Poljanšek K, Marin Ferrer M, De Groeve T, Clark I (Eds) Science for disaster risk management 2017: knowing better and losing less. EUR 28034 EN, Publications Office of the European Union, Luxembourg, pp 443-515 and refs therein. https://doi.org/10.2788/842809

Yovkov P, Karakanovski L, Strümpel C, Kloyber C, Torrossian H (2015) Community-based emergency preparedness exercise (CBE) guide, funded by the EU Civil Protection Financial Instrument. Grant Agreement Number: ECHO/SUB/1012/640926/Aware\&Resilient. www.ar-project.eu

Publisher's Note Springer Nature remains neutral with regard to jurisdictional claims in published maps and institutional affiliations. 